\title{
Knowledge and Skills Gap of Midwives to Conduct Obstetric Ultrasonography Screening in Primary Health Care Facilities in Kajiado and Kisii Counties, Kenya
}

\author{
Micah Matiang'i*, Priscilla Ngunju, Josephat Nyagero, Jarim Omogi \\ Amref International University, Nairobi, Kenya \\ Email: ^micyiego@yahoo.com, ^Micah.Matiangi@amref.org
}

How to cite this paper: Matiang'i, M., Ngunju, P., Nyagero, J. and Omogi, J. (2020) Knowledge and Skills Gap of Midwives to Conduct Obstetric Ultrasonography Screening in Primary Health Care Facilities in Kajiado and Kisii Counties, Kenya. Open Journal of Clinical Diagnostics, 10, 65-79. https://doi.org/10.4236/ojcd.2020.102006

Received: February 7, 2020

Accepted: June 27, 2020

Published: June 30, 2020

Copyright $\odot 2020$ by author(s) and Scientific Research Publishing Inc. This work is licensed under the Creative Commons Attribution International License (CC BY 4.0).

http://creativecommons.org/licenses/by/4.0/

\section{(c) (i) Open Access}

\begin{abstract}
Background: Ultrasound remains a tool of much importance in maternity care with midwives regarded as key health professionals when it comes to care of pregnant mothers. There is however limited study on the knowledge and skills gaps of midwives in conducting obstetric ultrasonography screening. The purpose of this study was to assess the specific obstetric ultrasonography knowledge and skills gaps among midwives based in primary health care facilities. Methods: A cross-sectional study employing both qualitative and quantitative method was conducted between July and August 2019 with 274 midwives. A structured questionnaire was used to collect data while Focus group discussion and Key Informants Interview were used to collect qualitative data. Descriptive statistics were used to summarize the data test associations between variables while the qualitative data were used to compliment the questionnaire data in eliciting more information on the gaps. Findings: Almost all (94.5\%) the midwives had never been trained on any basic obstetric ultrasound while six of those that had been trained in early stages by the project lacked equipment to practice the acquired skills. More than three quarters of the respondents opined that they wished to provide personalized care services to mothers/clients seeking Antenatal Care Services (ANC) in their community at a fee while only $13.9 \%$ had knowledge that obstetric screening should be done before 24 weeks gestation. Four out of ten of the respondents scored themselves a one (1) on the level of confidence they have using an ultrasound machines or technology. Conclusion: There still remains a huge gap as far as training of midwives on basic ultrasound screening is
\end{abstract}


concerned. The lack of basic obstetric ultrasound screening skills is a barrier to rolling out Point of Care Ultrasound (POCUS) screening services. However, midwives are motivated and willing to learn basic ultrasonography skills to further the objectives of Universal Health Coverage (UHC). Concerted efforts should be made to train midwives on basic obstetric ultrasonography skills in addition to availing mobile/hand held ultrasound technology in Primary Health facilities for them to apply the transferred skills. A sustainable business model to enable mothers continuously afford the services is critical as well.

\section{Keywords}

Antenatal Care, Basic Ultrasound Screening, Midwives, Primary Health Care

\section{Introduction}

In response to the Astana declaration (2018), strengthening Primary Health Care (PHC) is the most efficient, fair and cost-effective way to achieve lasting health impacts in developing countries. Although, between 1990 and 2015, there was a global drop of Maternal Mortality Ratio from 385 to 216/100,000 live births and 488 to $362 / 100,000$ live births in Kenya, mothers continue to die from preventable morbidities (MMEIG report 2015). The World Health Organisation (WHO) recommends at least one ultrasound screen for pregnant women before 24 weeks gestation and the International Federation of Gynaecology \& Obstetrics (FIGO, 2014) recommends at least two ultrasound examinations for all pregnant women. Unfortunately most women in Africa go through pregnancy without the benefit of a single ultrasound examination [1]. Ultrasound technology has been used to determine various foetal anomalies [2] which creates an opportunity for early referral for specialized care [3] [4]. However, unequal distribution and high cost of obstetric ultrasound technology has created a barrier to mothers accessing the essential service in developing countries.

There is evidence that midwives can learn basic ultrasound skills [5] [6] and such diagnostic care is not only beneficial but also leaves pregnant women more satisfied when they know early enough the status of their pregnancy [7]. Therefore Point of Care Obstetric Ultrasound Services (POCUS) in maternity care is a critical intervention in primary health care levels where mothers have limited access to basic diagnostic services. Midwives and nurses are the majority service providers in health facilities at the primary health care facilities yet they have limited access to basic tools to improve the quality of Antenatal Care. This presents an opportunity to train them on basic obstetric ultrasound skills using the innovative portable mobile apps e.g. Lumify ultrasound technology focusing on the critical parameters for antenatal mothers. There is however limited study on the knowledge and skills gaps of midwives in conducting obstetric ultrasonography 
screening in primary health care facilities in developing countries. The purpose of this study was to assess the specific basic obstetric ultrasonography knowledge and skills gaps among midwives based in underserved primary health care settings of Kajiado and Kisii counties-Kenya. Although there is no documented evidence that early pregnancy ultrasonography has a direct impact on maternal and neonatal mortality [6], there is also limited evidence on the sustainable business models that can sustainably enable mothers access the latest obstetric ultrasonography technological innovations in a low income country setting.

\section{Method}

\subsection{Study Design and Location}

A descriptive cross-sectional mixed method study was undertaken among midwives in Kisii and Kajiado Counties in Kenya. According to Kenya National Bureau of Statistics (KNBS) Kisii County has a population of 1,266,860 while Kajiado has $1,157,873$. The two counties are largely rural but includes peri-urban areas. The midwives in the two Counties are homogenous professionally given that they undergo the same training. A list of all primary health facilities were stratified by region (Kajiado and Kisii) and by type of facility (public and nonpublic). The facilities were then purposively selected to ensure representation of views both from the public and non-public primary health care facilities in the two Couties. Having obtained a list of the nurses in the respective primary health facilities, a systematic sampling was used in selecting the nurses mid wives to be interviewed. Although Kajiado county is closer to the National Capital City County Nairobi as compared to Kisii county, both Counties have limited access to basic diagnostic technology for improved perinatal care in Primary Health Care settings.

\subsection{Data Collection}

A questionnaire, focus group discussions (FGD) with nurse mid-wives and mothers attending ante-natal care in Kisii and Kajiado Counties was conducted. Six research assistants, fluent in English, administered the questionnaires, facilitated FGDs and KII, and obtained informed consent from participants. The research assistants who were to have the ability to use computers and mobile phone applications, had a training in health or social sciences and were familiar with the respective regions had a two day training for this study. The questionnaire and consent forms were pre-tested with 27 respondents and revised based on feedback received.

A mobile application tool Open Data Kit (ODK) was used to collect quantitative data from the nurse mid-wives.

\section{Questionnaire}

During the study period, 274 nurse mid wives from the two Couties responded to the questionnaire. The interviewer-administered questionnaire included socio 
demographic characteristics, women access to ultrasound services and mid wives knowledge and skills on point of Care obstetric ultrasonography services.

The study assumed that when trained in the use of ultrasonography no difference in the understanding and use of technology between the midwives in the two Couties would exist. The study therefore adopted a two sample approach with the anticipated population proportions being $P_{1}(0.5)$ and $P_{2}(0.5)$ at a significance level of 0.005 .

\subsection{Focus Group Discussion and Key Informants Interviews}

All the respondents for the FGDs and KII were purposively selected based on their positions, knowledge and their availability to participate in the study. A total of four FGDs were conducted among midwives. In addition, Key Informants Interviews (KIIs) was carried out among two representatives of the nursing council of Kenya (NCK) and society of radiography in Kenya (SORK). One KII each was conducted to a member of the mid wives association of Kenya, representative of the Obstetrics and Gynecologists society of Kenya and respective Chief County nurses in the two Counties. Information collected through FGD and KII sought to compliment the questionnaire data in the gaps that exist as far as the knowledge and skills of the midwives on Point of Care obstetric ultrasonography screening (POCUS) at the Primary Health Care level. The qualitative data also described the obstetric ultrasonography knowledge and skills gaps among midwives based in primary health care facilities.

Each FGD lasted for 45 - 60 minutes and was audio taped after getting written consent from the participants.

The study protocol, data collection tools, and consent forms were reviewed and approved by Amref Ethics and Scientific Review Committee (ESRC). Further authorization was obtained from the relevant administrative authorities in Kajiado and Kisii Counties in Kenya.

\subsection{Data Management and Analysis}

\subsubsection{Questionnaire}

The questionnaire data already captured in ODK was later converted to excel. The data were later converted to SPSS version 25 that was used to calculate descriptive statistics for study variables. Tables and figures were used to graphically show the respective findings. Bivariate and logistic regression were used to identify predictive variables, and ORs with $95 \%$ confidence intervals and value were used to measure the strength of the associations.

\subsubsection{Focus Group Discussions}

FGDs were transcribed and translated from Swahili to English by the research assistants. Transcripts were checked against the audio recordings and cleaned to remove all the identifying information. After an initial reading of the transcript and field notes, codes were developed based on the main interview questions, prior literature, and emergent concepts from the data. The Principal Investigator 
and one Co-principal Investigator independently reviewed one transcript and developed a coding structure which was discussed among the other researchers and agreed upon. A thematic analysis was later conducted where individual codes were read in aggregate and a written summary developed. The analysis attempted to achieve equal and fair representation of the participant's opinions. We selected representative quotes to illustrate study findings and retained informal language.

\subsection{Limitations}

Being a snap survey is possible to have omitted respondents with the most reliable information

\section{Results}

\subsection{Questionnaire}

As shown in Table 1, Kisii County comprised of $69 \%$ of the respondents with $73.4 \%$ being female while $86.9 \%$ had a degree as their highest education level. More than $80 \%$ of the respondents were not satisfied with the income they receive from professional employment with only $27 \%$ indicating that they had an income above (USD 500). Public facility had the majority of the respondents (80.3\%) with nearly two thirds working in level 3 facilities. ANC clinic and labour ward had the highest deployment areas in terms of the midwives at $48.9 \%$ and $32.1 \%$ respectively. Access to ultrasound services in the two Counties was low with $20.4 \%$ access in Kajiado while Kisii had less than $10 \%$. Only $17.9 \%$ of the respondents from public facilities had access to an ultrasound machine as depicted in Table 2 but it was also reported that sometimes they are dormant for lack of technicians to operate them.

Table 1. Socio demographic characteristics of the respondents $(n=274)$.

\begin{tabular}{ccc}
\hline Variable & Frequency & Percentage \\
County & 189 & 68.98 \\
Kisii & 85 & 31.02 \\
Kajiado & & \\
Sex & 73 & 26.64 \\
Male & 201 & 73.36 \\
Female & & \\
Level of education & 23 & 8.39 \\
Diploma & 238 & 86.86 \\
Degree & 13 & 4.74 \\
Certificate & & \\
Net Income (Ksh) from work profession & 26 & 9.5 \\
\hline$\leq 20,000$ & & \\
\hline
\end{tabular}




\section{Continued}

\begin{tabular}{ccc}
\hline $21,000-30,000$ & 72 & 26.3 \\
$31,000-40,000$ & 53 & 19.3 \\
$41,000-50,000$ & 50 & 18.2 \\
$\geq 51,000$ & 73 & 26.6 \\
Type of facility working in & & \\
Private for profit & 36 & 13.14 \\
Private (Non Profit) & 18 & 6.57 \\
Public & 220 & 80.29 \\
Level of facility & & \\
Level 2 & 7 & 2.6 \\
Level 3 & 162 & 59.1 \\
Level 4 & 101 & 37.9 \\
Others (Level 1 level 5) & 4 & 1.4 \\
Deployment area & & \\
ANC clinic & 134 & 48.91 \\
Labour ward & 38 & 32.12 \\
Postnatal ward & 14.87 \\
Out-patient & & 5.11 \\
\hline & & 13.8 \\
\hline
\end{tabular}

Table 2. Access to ultrasound Services in the facilities $(\mathrm{n}=274)$.

\begin{tabular}{ccc}
\hline Variable & Frequency & Percentage \\
\hline County & 27 & \\
Kisii & 56 & $9.9 \%$ \\
Kajiado & & $20.4 \%$ \\
Level of facility & 1 & \\
Level 2 & 37 & $0.4 \%$ \\
Level 3 & 37 & 13.5 \\
Others & & $13.5 \%$ \\
Type of facility & 24 & $8.8 \%$ \\
Private for profit & 10 & $3.6 \%$ \\
Private for Non profit & 49 & 17.9 \\
Public & &
\end{tabular}

\subsection{Training and Motivation on Obstetric Ultrasound Screening Skills}

A whopping majority comprising of $260(94.5 \%)$ of the midwives responded that they have never been trained on any basic obstetric ultrasound screening skills. The remaining 15 (5.5\%) indicated that they had earlier been exposed to ANC ultrasound screening. Six (6) and nine (9) of the fifteen were from Kisii and Ka- 
jiado counties respectively; they had been trained in early stages of a midwives entrepreneurship project offered by Amref but they lacked equipment to practice (Table 3). In general midwives from both Kajiado (Peri-urban) and Kisii counties (rural) expressed willingness to learn the basic ultrasound screening skills but on bivariate analysis there was no association between type of county and desire or motivation to be trained.

The midwives were further asked to specify the skills they wish to learn on ultrasound screening and their feedback is as presented in Figure 1. In general the highly ranked skill the midwives wanted to learn is how to operate an ultrasound machine (98\%), confirm gestational age of a pregnancy (91\%) and fetal viability (91\%). A total of 269 (98.2\%) of the respondents said they were very motivated to learn the basic obstetric screening skills and they further Table 4 gave various reasons why they are motivated. On perceptions mothers may have, 271 (98.9\%) of the respondents believed that mothers will have no problem trusting the basic ultrasonography screening services being offered by a midwife.

\subsection{Midwives Knowledge on Point of Care Obstetric Ultrasonography Service}

More than three quarters (77.74\%) of the respondents opined that they wished to provide personalized care services to ANC mothers/clients in their community at a fee with the respondents listing birth preparation (95.8\%), nutrition education (94.4\%) and Post-natal education (92.5\%) among the additional services

Table 3. Association between county and midwives knowledge and perceptions on point of care obstetric ultrasonography services.

\begin{tabular}{|c|c|c|c|}
\hline \multirow[b]{2}{*}{ Variable } & \multicolumn{2}{|c|}{ County } & \multirow[t]{2}{*}{ Statistics } \\
\hline & Kajiado n (\%) & Kisii n (\%) & \\
\hline \multicolumn{4}{|c|}{$\begin{array}{l}\text { Do you believe a nurse-midwife can learn basic } \\
\text { obstetric ultrasound screening skills? }\end{array}$} \\
\hline $\begin{array}{l}\text { obstetric ultrasound scre } \\
\text { Yes }\end{array}$ & $85(100)$ & $185(97.88)$ & $\begin{array}{l}\chi^{2}=1.82 \\
P=0.177\end{array}$ \\
\hline No & 0 & $4(2.12)$ & \\
\hline \multicolumn{4}{|c|}{$\begin{array}{l}\text { Do you think mothers can trust a midwife to } \\
\text { offer basic ultrasound screening services? }\end{array}$} \\
\hline Yes & $84(98.82)$ & $187(98.94)$ & $\begin{array}{c}P=0.931 \\
P=\end{array}$ \\
\hline No & $1(1.18)$ & $2(1.06)$ & \\
\hline \multicolumn{4}{|c|}{$\begin{array}{l}\text { Have you ever been trained on essential } \\
\text { obstetric ultrasound screening skills? }\end{array}$} \\
\hline Yes & $9(10.59)$ & $6(3.17)$ & No statistic \\
\hline No & $76(89.41)$ & $183(96.83)$ & \\
\hline \multicolumn{4}{|c|}{$\begin{array}{l}\text { Are you personally motivated to learn basic } \\
\text { obstetric ultrasonography skills? }\end{array}$} \\
\hline Yes & $81(95.29)$ & $188(99.47)$ & No statistic \\
\hline No & $4(4.71)$ & $1(0.53)$ & \\
\hline
\end{tabular}


Table 4. Reasons why midwives are learning essentials of ultrasonography.

\begin{tabular}{ccc}
\hline $\begin{array}{c}\text { What motivates you to learn basic obstetric } \\
\text { ultrasonography Screening skills }\end{array}$ & Frequency & Percent \\
\hline Help mothers locally & 234 & $85.4 \%$ \\
Reduce adverse perinatal outcomes & 221 & $80.7 \%$ \\
Earn extra income & 154 & $56.2 \%$ \\
Self-satisfaction & 148 & $54.0 \%$ \\
Start own sonography business & 99 & $36.1 \%$ \\
Get promoted & 72 & $26.3 \%$ \\
Get redeployed & 40 & $14.6 \%$ \\
\hline
\end{tabular}

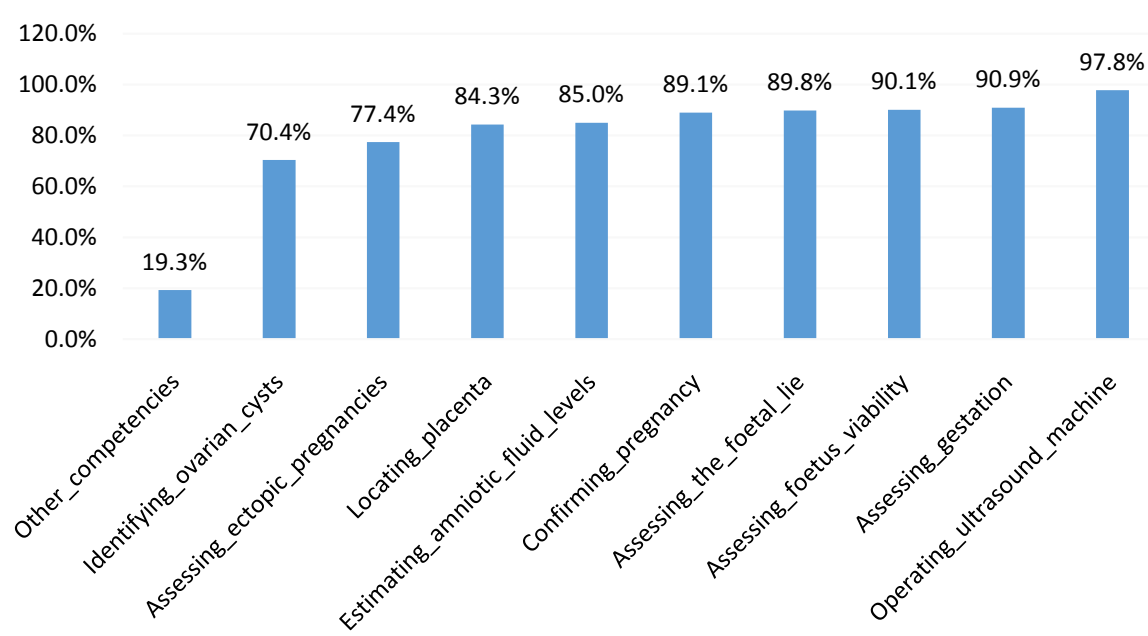

Figure 1. Skills midwives wish to learn on obstetric ultrasound screening.

they could provide to ANC mothers in a personalized community care arrangement. Only $13.9 \%$ of the 274 respondents had knowledge that obstetric screening should be done before 24 weeks gestation Figure 2. Notably, 110 (40\%) of the respondents on a scale of 1 to 5 (one being the least), scored themselves a one (1) on the level of confidence they have using a ultrasound machines.

\subsection{Association between County and ANC Clients Screening and Monitoring Practices at Service Delivery Points}

Significant difference were also observed between the Counties and ANC clients screening and monitoring practices at service delivery points; the factors included whether ANC clients are referred for ANC profiling $\left(\chi^{2}=14.05, P=\right.$ $0.000,0 \mathrm{R}=0.36,95 \% \mathrm{CI} 0.21-0.62)$, if pregnant women in the facilities have access to ultrasound screening services $\left(\chi^{2}=73.92, P=0.000,0 \mathrm{R}=0.86,95 \% \mathrm{CI}\right.$ $0.05-0.16)$, ability of mother to pay for ultrasound $\left(\chi^{2}=13.91, P=0.000,0 \mathrm{R}=\right.$ $0.35,95 \% \mathrm{CI}(0.20-0.61)$, and number of mothers refered $\left(\chi^{2}=18.59, P=0.000\right.$, $\mathrm{OR}=0.31,95 \% \mathrm{CI}(0.18-0.53)$.

The health workers in Kisii County were less likely (0.36 times p-value 0.000) to refer ANC clients for ANC profiling compared to the health workers in Kajiado. 


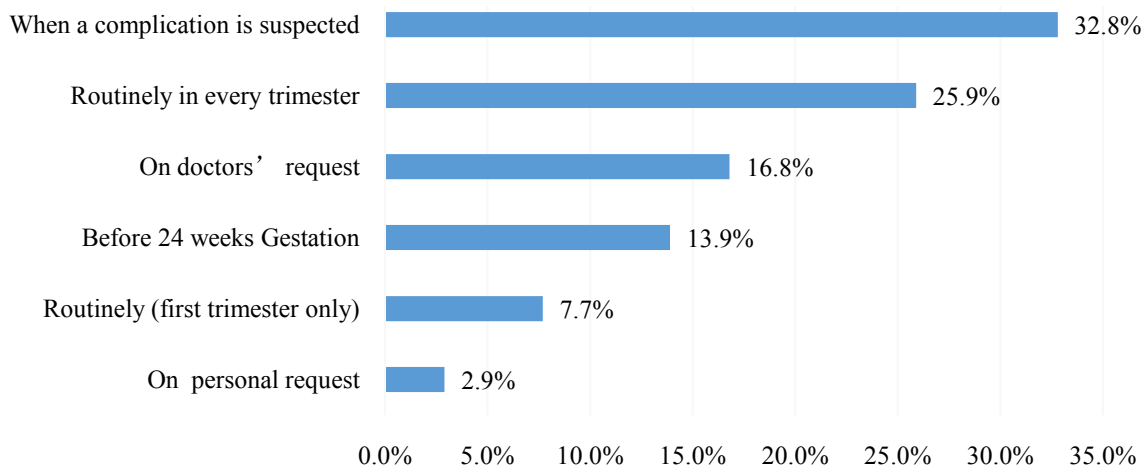

Figure 2. When pregnant woman should have an ultrasound screening.

Pregnant women in Kisii facilities were less likely (0.86 times $p$-value 0.000$)$ to have access to ultrasound screening services compared to their counterparts in Kajiado with mothers in visiting Kisii facilities less likely (0.35 times p-value 0.000 ) to have ability to pay for the ultrasound services as shown in Table 5.

In addition, the study found that $146(65.5 \%)$ of the midwives working in the public health facilities never access an ultrasound for the clients compared to only $10(4.5 \%)$ and $6(2.7 \%)$ working in private for profit and private for nonprofit facilities.

\subsection{Utilization of Available Ultrasound Services and Referral System}

Although $18 \%$ of the respondents from public facilities indicated that they had access to ultrasound machines in their facilities, the midwives further observed that mothers who seek ultrasound services are mainly in their $2^{\text {nd }}$ Trimester (72.62\%) and $3^{\text {rd }}$ trimester (26.19\%). Mostly mothers undertake an ultrasound screening upon referral from lower levels of the health system especially when they suspect a fetal death or abnormal hemorrhage (Figure 3). Notably, 58.8\% of the respondents do refer such mothers to levels 4 and 5 public health facilities (Figure 4) because they are cheaper as compared to private facilities where an ultrasound service costs USD 15 to USD 250. It is only $25.9 \%$ of the respondents who believed that obstetric ultrasound screening should be done routinely for pregnant women; $32 \%$ of the respondents indicated that ultrasound screening should only be done when a complication is suspected. Nevertheless nearly all respondents (98.18\%) thought it is very necessary for ANC mothers to access obstetric ultrasound screening services in their facilities.

\section{Discussion}

\subsection{Socio-Demographic Characteristics}

The female were the majority in this study and this confirms previous findings that women's share of employment in the health and social sector is high. However, according to a report done by WHO in 104 countries, there exist systematic differences in gender distribution by occupation across all regions. According to 


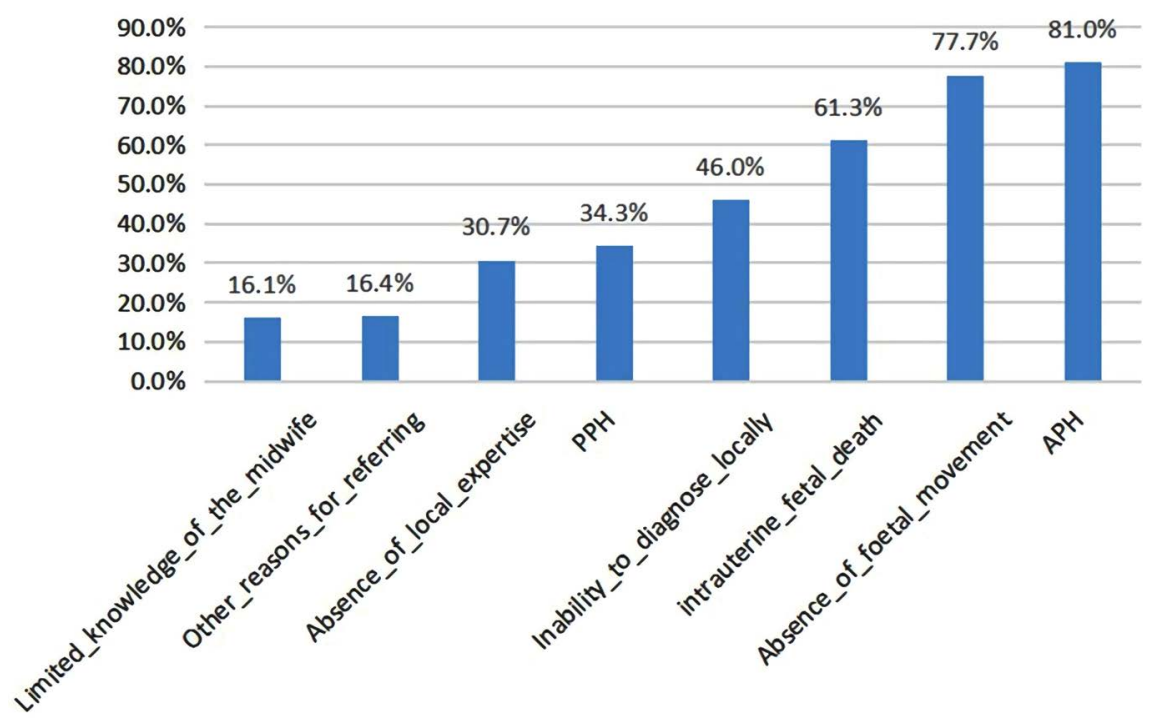

Figure 3. Reasons for referring mothers for ultrasound screening.

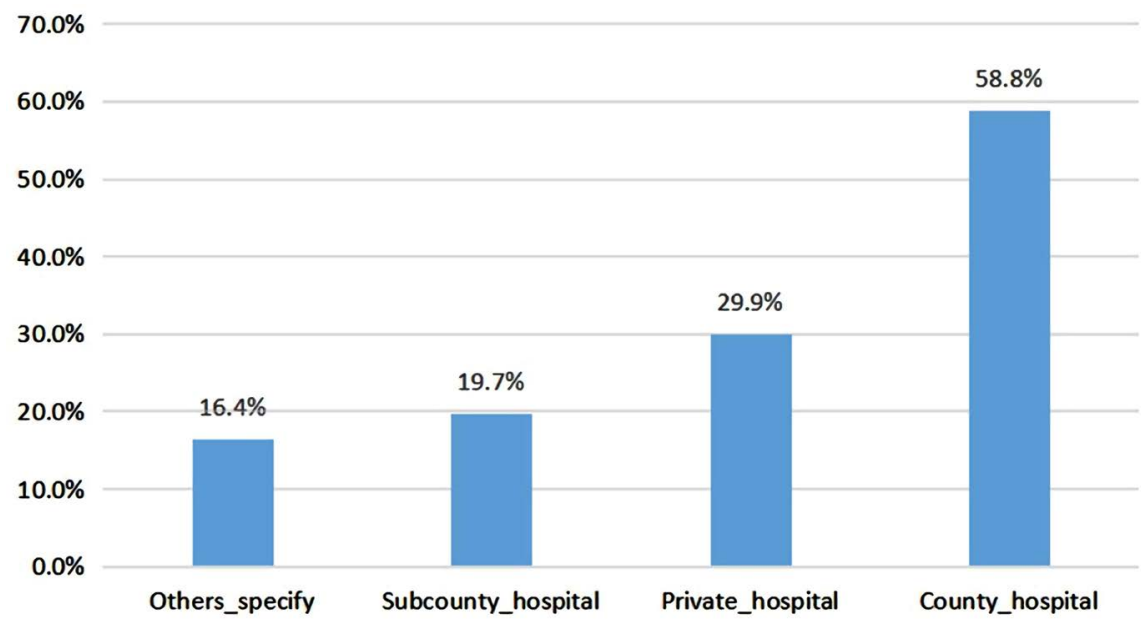

Figure 4. Where mothers are commonly referred to for ultrasound screening.

Table 5. Association between county and ANC clients screening and monitoring practices at service delivery points.

\begin{tabular}{cccc}
\hline & \multicolumn{2}{c}{ County } & Statistics \\
\hline Variable & Kajiado n (\%) & Kisii n (\%) & \\
\hline $\begin{array}{c}\text { How do you screen pregnant } \\
\text { mothers' ANC parameters }\end{array}$ & & \\
Manually & $22(25.88)$ & $25(13.23)$ & No statistic \\
Electronically & $4(4.71)$ & $3(1.59)$ & \\
Manual and electronic & $59(69.41)$ & $161(85.19)$ & \\
Do you refer ANC clients for ANC profiling? & & & $\chi^{2}=\mathbf{1 4 . 0 5}, \boldsymbol{P}=\mathbf{0 . 0 0 0}$ \\
Yes & $40(47.06)$ & $46(24.34)$ & $\mathbf{0 R}=\mathbf{0 . 3 6 , 9 5 \% ~ C I}$ \\
No & $45(52.94)$ & $143(75.66)$ & $(\mathbf{0 . 2 1}-\mathbf{0 . 6 2})$ \\
& & &
\end{tabular}




\section{Continued}

Do pregnant women in your facility have access to ultrasound screening services?

$\begin{array}{lll}\text { Yes } & 56(65.88) & 27(14.29) \\ \text { No } & 29(34.12) & 162(85.71)\end{array}$

Do you find it necessary for ANC mothers to access obstetric ultrasound screening services in your facility?

\section{Yes}

No

Cost of ultrasound

$<$ Ksh1001

$\geq$ Ksh 1001

Are mothers able to pay for ultrasound

$$
\begin{aligned}
& \text { Yes } \\
& \text { No }
\end{aligned}
$$

Number of mothers refereed

$$
\begin{aligned}
& <11 \text { Mothers } \\
& \geq 11 \text { Mothers }
\end{aligned}
$$

$$
29(34.12) \quad 162(85.71)
$$

$\mathrm{OR}=0.86,95 \% \mathrm{CI}$

(0.05 - 0.16)

$$
\begin{array}{ccc} 
& & \chi^{2}=2.29, P=0.130 \\
05(100 & 184(97.35) & \\
0 & 5(2.65) &
\end{array}
$$

$$
\begin{array}{ll}
23(27.06) & 70(37.04) \\
62(72.94) & 119(62.96)
\end{array}
$$

$$
\begin{array}{ccc}
36(42.35) & 39(20.63) & \begin{array}{c}
\chi^{2}=13.91, P=0.000 \\
\text { oR }=0.35,95 \% \mathrm{CI}
\end{array} \\
49(57.65) & 150(79.37) & (0.20-0.61)
\end{array}
$$

$\begin{array}{ccc}43(50.59) & 145(76.72) & \begin{array}{c}\chi^{2}=18.59, P=0.000 \\ \text { 0R }=0.31,95 \% \mathrm{CI}\end{array} \\ 42(49.41 & 44(23.28) & (0.18-0.53)\end{array}$

the report, male workers are significantly represented as physicians, dentists and pharmacists in the workforce, with female comprising the vast majority of the nursing and midwifery workforce [8].

Eight out of ten service providers worked in public sector. Our results are similar to those of African studies [9] [10]. This could be due to the fact that the public sector remains the major employer of health workers and the high number of public facilities both in Kisii and Kajiado.

\subsection{Knowledge and Skills Levels}

The lack of trained providers in point of care ultrasound is said to be a barrier to its utility in middle income countries leading to a demand for training courses directed at filling this need [11]. Training of health personnel is a key factor to implementation of quality obstetric ultrasound services since better management of patients relies on the ability of health personnel to use the machine proficiently and interpret findings accurately [12].

According to The International Society of Ultrasound Obstetrics and Gynecology (ISUOG), basic ultrasound examination should be done to investigate the fetal viability and fetal movements, detection of multiple pregnancy, assessment of gestational age and fetal size by recording biometric measurements, evaluation of amount of amniotic fluid, placenta location and fetal position [13].

According to $\mathrm{WHO}$, there should be a minimum of $3-6$ months of training accompanied with 300 - 500 examinations for the general ultrasonography cur- 
riculum [14]. At the same time, multiple studies have concluded that health professional, mainly midwives can be trained to perform point of care ultrasound to identify high risk pregnancies that can lead to allow cost improvement strategy in maternity services [2] [6]. This is consistent with our study in which almost all midwives believed that a nurse-midwife can learn basic obstetric ultrasound screening skills.

The training of the midwives on basic obstetric ultrasound remains very low among the respondents in this study with 9 out 10 confirming that they are yet to receive training on basic obstetric ultrasound. The figures are quite higher compared to a report in which $38.3 \%$ of service providers were found to have no training at all [2] [12]. Studies show that insufficient training for healthcare providers is the primary barrier to regular use of obstetric ultrasound [15] with a qualitative study done among Rwandan midwives showing that apart from offering a formal training for physicians, there is need for introduction of ultrasound training for midwives in order to decrease the burden of work in hospitals and to improve access to ultrasound at healthcare centers particularly in rural areas [7]. The motivation to learn basic obstetric ultrasound was high among those yet to learn and this is consistent with a study by Shah [15].

Our study shows a shortfall in the level of knowledge on the ideal time to perform a fetal biometry and this is higher compared to a study in Guinea in which 69.2\% had no idea of the ideal time to perform a fetal biometry. The higher figures might be due to the fact that the study was done among midwives unlike the study in Guinea that was done majorly among obstetric gynecologists [16].

Our study found a significant difference in referral for ultrasonography, access to ultrasonography services, and the ability to pay for the services in the two Counties.

On access to ultrasound services for their clients, our study was consistent to a cross sectional study done in Rwanda in which participants from public health facilities were less likely to report access to obstetric ultrasound when needed compared to participants from private health facilities [15]. The study is also consistent with a surveys conducted across Canada and the United States that identified a lack of equipment, training and inability to maintain skills as major barriers to point-of care ultrasound (POCUS) [17].

Kisii being a rural set-up, the midwives reported that their clients are less likely to access ultrasound unlike those in Kajiado that is peri-urban. In the study done in Rwanda, participants employed at health facilities outside Kigali area were less likely to report access to obstetric ultrasound when needed than participants employed at health facilities in the Kigali area [3]. According to a 25 question online survey from 44 countries, some of the barriers to use of ultrasound include lack of training, lack of equipment, ultrasound machine malfunction and lack of maintenance [15].

A majority of the midwives indicated that they would love to learn basic ultrasound screening services and this is consistent with a qualitative study done in Rwanda [18] in which physicians interviewed believed that it would be one 
important strategy to improve care for pregnant women particularly the poorest in rural areas who were less likely to be seen by physicians during pregnancy, to reduce the burden on physicians and to reduce delay in decision making. In addition, with the shortage of physicians in rural areas, means that midwives or nurses are to manage complicated deliveries, putting a high responsibility on their shoulders.

\section{Conclusion}

Ultrasound has the capability to markedly improve diagnostic services hence improving the detection of high risk pregnancies and increased ANC attendance. However, the success of this important diagnostic tool depends on the level of knowledge and skill of the operator as well as its availability. Our current study identified lack of knowledge and skills, limited access to ultrasound technology, high cost ultrasound diagnostic services and limited number of experts in the facilities as the main challenges to mothers accessing the service before 24 weeks gestation.

\section{Recommendations}

Previous studies have demonstrated that training midwives to perform obstetric ultrasound is both feasible and practical more so when combined with quality assurance and closer mentorship and supervision.

This study adds to the current knowledge on some of the gaps on knowledge and skills among midwives that need to be addressed. Midwives need to possess more knowledge and skills in use of ultrasound to assist them play their role and responsibilities effectively.

Given the urge and motivation of the midwives to ultrasonography training, there is need for developing content rich distance learning modules, well thought and creative sustainable programs for training, mentorship and supervision.

\section{Authors' Contributions}

Matiang'i M designed, coordinated and oversaw the study in Kenya, Nyagero J supervised the data management, Ngunju P supervised the enumerators while Omogi $\mathrm{J}$ assisted in data management. All authors read and approved the manuscript.

\section{Acknowledgements}

Amref International University and its sponsor Amref Health Africa are grateful to the National Government (MOH), Kajiado and Kisii County Governments as well as the private clinics and communities involved in the study. Appreciation is extended to Phillips Foundation for their generous financial support; and June Victoria Omollo (Royal Philips-Africa) for her technical review of the study protocol. 


\section{Conflicts of Interest}

The authors declare no competing interests.

\section{References}

[1] Wanyonyi, S.Z., Mariara, C.M., Vinayak, S. and Stones, W. (2017) Opportunities and Challenges in Realizing Universal Access to Obstetric Ultrasound in Sub-Saharan Africa. Ultrasound International Open, 3, E52-E59. https://doi.org/10.1055/s-0043-103948

[2] Kim, E.T., Singh, K., Moran, A., Armbruster, D. and Kozuki, N. (2018) Obstetric Ultrasound Use in Low and Middle Income Countries: A Narrative Review. Reproductive Health, 15, Article No. 129. https://doi.org/10.1186/s12978-018-0571-y

[3] Holmlund, S., Ntaganira, J., Edvardsson, K., Lan, P.T., Semasaka Sengoma, J.P., Lesio Kidanto, H., Ngarina, M., Small, R. and Mogren, I. (2018) Health Professionals' Experiences and Views on Obstetric Ultrasound in Rwanda: A Cross-Sectional Study. PLoS ONE, 13, e0208387. https://doi.org/10.1371/journal.pone.0208387

[4] Franklin, H.L., Mirza, W., Swanson, D.L., Newman, J.E., Goldenberg, R.L., Muyodi, D., Figueroa, L., Nathan, R.O., Swanson, J.O., Goldsmith, N., Kanaiza, N., Naqvi, F., Pineda, I.S., López-Gomez, W., Hamsumonde, D., Bolamba, V.L., Fogleman, E.V., Saleem, S., Esamai, F., et al. (2018) Factors Influencing Referrals for UltrasoundDiagnosed Complications during Prenatal Care in Five Low and Middle Income Countries. Reproductive Health, 15, Article No. 204. https://doi.org/10.1186/s12978-018-0647-8

[5] Dalmacion, G.V., Reyles, R.T., Habana, A.E., et al. (2018) Handheld Ultrasound to Avert Maternal and Neonatal Deaths in 2 Regions of the Philippines: An iBuntis ${ }^{\infty}$ Intervention Study. BMC Pregnancy Childbirth, 18, Article No. 32. https://doi.org/10.1186/s12884-018-1658-8

[6] Vinayak, S., Sande, J., Nisenbaum, H. and Nolsøe, C.P. (2017) Training Midwives to Perform Basic Obstetric Point-of-Care Ultrasound in Rural Areas Using a Tablet Platform and Mobile Phone Transmission Technology-A WFUMB COE Project. Ultrasound in Medicine \& Biology, 43, 2125-2132. https://doi.org/10.1016/j.ultrasmedbio.2017.05.024

[7] Holmlund, S., Ntaganira, J., Edvardsson, K., Lan, P.T., Semasaka Sengoma, J.P., Åhman, A., Small, R. and Mogren, I. (2017) Improved Maternity Care If Midwives Learn to Perform Ultrasound: A Qualitative Study of Rwandan Midwives' Experiences and Views of Obstetric Ultrasound. Global Health Action, 10, Article ID: 1350451. https://doi.org/10.1080/16549716.2017.1350451

[8] Magar, V., Gerecke, M., Dhillon, I. and Campbell, J. (2017) Women's Contributions to Sustainable Development through Work in Health: Using a Gender Lens to Advance a Transformative 2030 Agenda. WHO. https://www.who.int/bulletin/volumes/96/9/18-211607/en/

[9] Mubuuke, A., Kiguli-Malwadde, E., Businge, F. and Byanyima, R. (2011) Utilisation of Obstetric Sonography at a Peri-Urban Health Centre in Uganda. Pan African Medical Journal, 7, 7-24. https://doi.org/10.4314/pamj.v7i1.69139

[10] Solom, L., Bernard, J. and Vile, Y. (2004) First Trimester Ultrasound Should Be a Tailored Examination. Journal de Gynécologie Obstétrique et Biologie de la Reproduction, 33, 375-377.

[11] Bentley, S., Hexom, B. and Nelson, B.P. (2015) Evaluation of an Obstetric Ultrasound Curriculum for Midwives in Liberia. Journal of Ultrasound in Medicine, 34, 
1563-1568. https://doi.org/10.7863/ultra.15.14.08017

[12] Stanton, K. and Mwanri, L. (2013) Global Maternal and Child Health Outcomes: The Role of Obstetric Ultrasound in Low Resource Settings.

http://pubs.sciepub.com/jpm/1/3/3/

[13] ISUOG (2014) ISUOG Education Committee Recommendations for Basic Training in Obstetric and Gynecological Ultrasound. Ultrasound in Obstetrics \& Gynecology, 43, 113-116. https://doi.org/10.1002/uog.13208

[14] WHO (2016) World Health Organization Recommendations on Antenatal Care for a Positive Pregnancy Experience: Ultrasound Examination.

https://www.who.int/reproductivehealth/publications/maternal perinatal health/an c-positive-pregnancy-experience/en/

[15] Shah, S., Bellows, B.A., Adedipe, A.A., Totten, J.E., Backlund, B.H. and Sajed, D. (2015) Perceived Barriers in the Use of Ultrasound in Developing Countries. Critical Ultrasound Journal, 7, Article No. 11.

https://doi.org/10.1186/s13089-015-0028-2

[16] Telly, S.Y., Leno, D.W.A., Camara, M.K., Hyjazi, Y. and Keita, N. (2017) Knowledge, Attitudes and Practices of Obstetrical Ultrasound in Conakry, Guinea. International Journal of Reproduction, Contraception, Obstetrics and Gynecology, 6, 585. https://doi.org/10.18203/2320-1770.ijrcog20170387

[17] Micks, T., Sue, K. and Rogers, P. (2016) Barriers to Point-of-Care Ultrasound Use in Rural Emergency Departments. Canadian Journal of Emergency Medicine, 18, 475479. https://doi.org/10.1017/cem.2016.337

[18] Edvardsson, K., Ntaganira, J., Åhman, A., Sengoma, J.P.S., Small, R. and Mogren, I. (2016) Physicians' Experiences and Views on the Role of Obstetric Ultrasound in Rural and Urban Rwanda: A Qualitative Study. Tropical Medicine \& International Health, 21, 895-906. https://doi.org/10.1111/tmi.12718 